\title{
PENGERTIAN DARI KARAKTERISTIK DIAGNOSA DAN MENERAPKAN PROSES PENGUMPULAN DATA SESUAI DENGAN STANDAR
}

\author{
Agnes Jessica Lubis
}

Jessikaagnes8@gmail.com

\section{Latar belakang}

Penegakan pada diagnosis adalah aspek penting dalam praktik dan tindakan dalam keperawatan. Sepanjang waktu, format serta kualitas terhadap penegakan diagnosis telah berkembang, tetapi lebih fokusnya terus berdampak terhadap perawatan klien (Potter \& Perry; 2009). Sistem penegakan diagnosis yang ideal harus memberikan informasi klien yang komprehensif, menunjukkan hasil dan standar klien, memfasilitasi reimbursement dari pemerintah dan dari perusahaan asuransi pembayar, serta berfungsi sebagai dokumen legal (Twardon dan Gartner, 1993: Potter \& Perry; 2009). Mutu asuhan keperawatan dapat tergambar dari penegakan diagnosis proses keperawatan (Gillies, 1994). Penegakan diagnosis dalam keperawatan memegang peranan penting terhadap segala macam tuntutan masyarakat yang semakin kritis dan mempengaruhi kesadaran masyarakat akan hak-haknya dari suatu unit kesehatan.

Diagnosis keperawatan adalah penilaian klinis terhadap pengalaman ataupun respon terhadap individu, keluarga, atau komunitas pada masalah kesehatan atau risiko masalah kesehatan atau pada proses kehidupan. Diagnosis keperawatan merupakan bagian vital dalam menentukan asuhan keperawatan yang sesuai untuk membantu klien mencapai kesehatan yang optimal. Perawatan yang profesional dicerminkan dalam pendokumentasian yang profesional, yang membuktikan tentang apa yang dilakukan oleh perawat dan secara efektif menggambarkan status dan kemajuan klien. Informasi yang menggambarkan masalah klien atau diagnosis keperawatan kemudian mengarah pada pemberian asuhan keperawatan untuk memilih suatu rencana perawatan yang sesuai dengan terapi keperawatan (Potter \& Perry; 2009)

PPNI merupakan Organisasi Profesi (OP) yang diakui dalam UU Keperawatan memiliki bertanggung jawab dalam meningkatkan dan mengembangkan pengetahuan dan keterampilan, martabat, dan etika profesi perawat di Indonesia. Dalam mencapai tujuan dan menjalankan 
fungsi tersebut, salah satunya PPNI berkewajiban untuk menyusun standar-standar yang meliputi standar kompetensi, standar asuhan keperawatan, dan standar kinerja profesional. Standar asuhan keperawatan dibutuhkan Standar Diagnosis Keperawatan, oleh karena PPNI menerbitkan Standar Diagnosis Keperawatan Indonesia (SDKI).

Diagnosis keperawatan telah diterapkan di berbagai rumah sakit dan fasilitas kesehatan lainnya, namun pengetahuan perawat terkait indikator-indikator diagnostik untuk penegakan diagnosis masih perlu ditingkatkan agar penegakan dapat dilakukan secara tepat dan terstandarisasi, serta proses penegakan diagnosisi tidak dianggap sulit. Tanpa terminologi dan indikator yang terstandarisasi, penegakan diagnosis keperawatan menjadi tidak seragam, tidak akurat dan ambigu sehingga menyebabkan ketidaktepatan pengambilan keputusan dan ketidaksesuaian asuhan keperawatan yang diberikan kepada klien.

\section{Metode}

Metode ini digunakan secara faktual dengan merujuk pada referensi referensi yang dapat dipercaya seperti contohnya ialah jurnal jurnal, e-book, serta buku teks. Dengan menggabungkan referensi referensi yang faktual tentang pengertian dari karakteristik diagnose dan menerapkan pengumpulan data sesuai dengan standar standar yang telah ditentukan, maka penulis berharap artikel ini dapat membantu orang orang yang membutuhkan informasi tentang karakteristik diagnosa dan menerapkan proses pengumpulan data sesuai dengan standar

\section{Hasil}

Karakteristik Perawat dan Perawat adalah seorang profesional yang mempunyai kemampuan, tanggung jawab dan kewenangan melaksanakan pelayanan asuhan keperawatan dari berbagai jenjang pelayanan keperawatan. Pemenuhan kebutuhan serta kepuasan pasien selama di rumah sakit diperlukan tenaga kesehatan yang harus mempunyai pengetahuan (knowledge), keterampilan (skill) yang tinggi serta mempunyai sikap profesional (attitude) dan dapat menunjang pembangunan kesehatan. Pelayanan yang diberikan akan berkualitas dan dapat memberikan kepuasan pada pasien sebagai penerima pelayanan maupun perawat sebagai pemberi pelayanan (Hamid,2000). 
Diagnosa keperawatan adalah suatu bagian yang integral dari proses Keperawatan yang ada. Hal ini merupakan komponen dari setiap langkah - langkah analisa, dimana perawat harus melakukan identifikasi terhadap respon-respon individu terhadap masalah-masalah kesehatan yang aktual serta potensial. Dibeberapa negara diagnosa diidentifikasikan dalam tindakan praktik keperawatan sebagai suatu tanggung jawab legal dari perawat yang professional. Diagnosa keperawatan memberikan dasar petunjuk untuk memberikan terapi yang pasti di mana perawat yang bertanggung jawab di dalam ruangan rawat.

Proses keperawatan merupakan aktivitas yang mempunyai arti tersendiri yaitu praktik keperawatan yang dilakukan dengan cara yang sistematik. Selama melaksanakan proses keperawatan, perawat menggunakan dasar pengetahuan yang komprehensif untuk mengkaji status kesehatan klien, membuat penilaian yang bijaksana dan mendiagnosa, mengidentifikasi hasil akhir kesehatan klien dan merencanakan, menerapkan dan mengevaluasi tindakan keperawatan yang tepat guna mencapai hasil akhir tersebut (Dermawan, 2012).

Tujuan dari proses keperawatan menurut Manurung (2011) ialah sebagai berikut: a. Mempraktikkan metode pemecahan masalah dalam praktik keperawatan. b. Menggunakan standar untuk praktik keperawatan. c. Memperoleh metoda yang baku dan sesuai, rational dan sistematis dalam memberikan asuhan keperawatan pada pasien. d. Memperoleh metoda yang dapat digunakan dalam segala situasi e.Memperoleh hasil asuhan keperawatan dengan kualitas tinggi. Proses keperawatan memiliki komponen komponen yaitu pengkajian, tujuan dari pengkajian tersebut, tipe data, hal hal yang harus diperhatikan dalam pengkajian.

Kriteria diagnose antara lain sebagai berikut ( Nursalam, 2015 ) :

1) Status kesehatan dibandingkan dengan standar untuk menentukan kesenjangan.

2) Diagnosa keperawatan dihubungkan dengan penyebab kesenjangan dan pemenuhan kebutuhan pasien.

3) Diagnosa keperawatan dibuat sesuai dengan wewenang.

4) Komponen diagnosa terdiri atas PE/PES.

5) Pengkajian ulang dan revisi terhadap diagnosis berdasarkan data terbaru 


\section{Pembahasan}

Proses keperawatan merupakan suatu proses yang sistematis dalam pengumpulan data dari berbagai sumber data untuk mengevaluasi dan mengidentifikasi status kesehatan klien.Pengkajian keperawatan merupakan dasar pemikiran dalam memberikan asuhan keperawatan sesuai dengan kebutuhan klien. Pengkajian yang lengkap, dan sistematis sesuai dengan fakta atau kondisi yang ada pada klien sangat penting untuk merumuskan suatu diagnosa keperawatan dan dalam memberikan asuhan keperawatan sesuai dengan respon individu.

1. Pengumpulan Data Pada saat Anda melakukan pengkajian keperawatan Anda harus tahu macam data yang ingin diperoleh ketika Anda melakukan pengkajian pada klien Anda?Data-data yang harus Anda peroleh ketika Anda melakukan pengkajian pada klien, Anda seperti:

$\checkmark$ Data Dasar adalah seluruh informasi tentang status kesehatan klien, data dasar ini meliputi data umum, data demografi, riwayat keperawatan, pola fungsi kesehatan dan pemeriksaan. Data dasar yang menunjukkan pola fungsi kesehatan efektif/optimal merupakan data yang dipakai dasar untuk menegakkan diagnosa keperawatan sejahtera.

$\checkmark$ Data Fokus Data focus adalah informasi tentang status kesehatan klien yang menyimpang dari keadaan normal. Data focus dapat berupa ungkapan klien maupun hasil pemeriksaan langsung Anda sebagai seorang perawat. Data ini yang nantinya mendapat porsi lebih banyak menjadi dasar timbulnya masalah keperawatan. Segala penyimpangan yang berupa keluhan hendaknya dapat divalidasi dengan data hasil pemeriksaan. Sedangkan untuk bayi atau klien yang tidak sadar banyak menekannya pada data focus yang berupa hasil pemeriksaan.

$\checkmark$ Data Subjektif Data yang merupakan ungkapan keluhan klien secara langsung dari klien maupun tidak langsung melalui orang lain yang mengetahui keadaan klien secara langsung dan menyampaikan masalah yang terjadi kepada Anda sebagai perawat berdasarkan keadaan yang terjasi pada klien. Untuk mendapatkan data subjektif, dilakukan anamnesis, salah satu contoh: "merasa pusing", "mual", "nyeri dada" dan lainlain.

$\checkmark$ Data Objektif Data yang diperoleh Anda secara langsung melalui observasi dan pemeriksaan pada klien. Data objektif harus dapat diukur dan diobservasi, bukan 
merupakan interpretasi atau asumsi dari Anda, contoh: tekanan darah 120/80 mmHg, konjungtiva anemis.

2. Sumber Data Keperawatan, Setelah Anda memahami tentang jenis-jenis data, mari kita lanjutkan dengan materi selanjutnya, yaitu tentang sumber data keperawatan sesuai dengan jenis data yang anda inginkan. Apakah Anda tahu dari mana sumber data tersebut dapat Anda peroleh. Sumber-sumber data yang dapat kita peroleh sesuai dengan jenis data yang kita perlukan dalam pengkajian, seperti:

a) Sumber data primer Klien adalah sebagai sumber utama data (primer) dan Anda dapat menggali informasi yang sebenarnya mengenai masalah kesehatan klien. Apabila klien dalam keadaan tidak sadar, mengalami gangguan bicara, atau pendengaran, klien masih bayi atau karena beberapa sebab klien tidak dapat memberikan data subjektif secara langsung, Anda dapat menggunakan data objektif untuk menegakkan diagnosis keperawatan. Namun, apabila diperlukan klarifikasi data subjektif, hendaknya Anda melakukan anamnesis pada keluarga.

b) Sumber data sekunder Sumber data sekunder adalah data yang diperoleh selain klien, yaitu Orang terdekat, orang tua, suami atau istri, anak, teman klien, jika klien mengalami gangguan keterbatasan dalam berkomunikasi atau kesadaran yang menurun, misalnya klien bayi atau anak-anak, atau klien dalam kondisi tidak sadar.

c) Sumber data lainnya

$\checkmark$ Catatan medis dan anggota tim kesehatan lainnya. Catatan kesehatan terdahulu dapat Anda gunakan sebagai sumber informasi yang dapat mendukung rencana tindakan perawatan.

$\checkmark$ Riwayat penyakit. Pemeriksaan fisik dan catatan perkembangan merupakan riwayat penyakit dapat Anda peroleh dari terapis. Informasi yang diperoleh adalah hal-hal yang difokuskan pada identifikasi patologis dan untuk menentukan rencana tindakan medis.

$\checkmark$ Konsultasi. Kadang terapis memerlukan konsultasi dengan anggota tim kesehatan spesialis, khususnya dalam menentukan diagnosa medis atau dalam merencanakan dan melakukan tindakan medis. Informasi tersebut dapat Anda ambil untuk membantu menegakkan diagnosa. 
$\checkmark$ Hasil pemeriksaan diagnostik. Seperti hasil pemeriksaan laboratorium dan tes diagnostik, dapat Anda gunakan sebagai data objektif yang dapat disesuaikan dengan masalah kesehatan klien. Hasil pemeriksaan diagnostik dapat Anda gunakan membantu mengevaluasi keberhasilan dari tindakan keperawatan.

Teknik teknik yang wajib diterapkan dalam Proses pengumpulan data :

a. Anamnesis : suatu proses tanya jawab atau komunikasi untuk mengajak klien dan keluarga bertukar fikiran dan perasaan, mencakup keterampilan secara verbal dan non verbal, empati dan rasa kepedulian yg tinggi. Teknik Verbal, meliputi: pertanyaan terbuka/tertutup, menggali jawaban dan memvalidasi respon klien. Sedangkan teknik non Verbal, meliputi: mendegarkan secara aktif, diam, sentuhan dan kontak mata. Unsurunsur penting yang harus Anda cermati dalam mendengar secara aktif, meliputi:

$\checkmark$ Memperhatikan pesan yg disampaikan dan hubungannya dengan fikiran

$\checkmark$ Mengurangi hambatan-hambatan

$\checkmark$ Posisi duduk Anda yg sesuai

$\checkmark$ Menghindari interupsi

$\checkmark$ Mendengarkan secara seksama setiap perkataan klien

$\checkmark$ Memberi kesempatan istirahat kepada klien

tujuan komunikasi yang perawat lakukan dalam pengkajian data keperawatan meliputi:

$\checkmark$ Mendapatkan informasi yang Anda perlukan dalam mengidentifikasi dan merencanakan tindakan keperawatan

$\checkmark$ Meningkatkan hubungan Anda dengan klien dalam komunikasi

$\checkmark$ Membantu klien memperoleh informasi dan berpartisipasi dalam identifikasi masalah dan tujuan

$\checkmark$ Membantu Anda untuk menentukan investigasi lebih lanjut selama tahap pengkajian.

b. Observasi Tahap kedua pada pengumpulan data yang Anda lakukan adalah Observasi, yaitu: pengamatan prilaku dan keadaan klien untuk memperoleh data tentang masalah kesehatan $\cong v$ Konsep Dasar Keperawatan $\cong v 233$ dan keperawatan klien. Kegiatan observasi, meliputi 2 S HFT: Sight yaitu seperti kelainan fisik, perdarahan, terbakar, 
menangis; Smell yaitu seperti alkohol, darah, feces, medicine, urine; Hearing yaitu seperti tekanan darah, batuk, menangis, ekspresi nyeri, heart rate dan ritme

c. Pemeriksaan Fisik Pemeriksaan fisik yang Anda lakukan dengan menggunakan metode atau teknik P.E. (Physical Examination) yang terdiri dari :

$>$ Inspeksi, yaitu: teknik yang dapat Anda lakukan dengan proses observasi yang dilaksanakan secara sistematik.

$>$ Palpasi, yaitu: suatu teknik yang dapat Anda lakukan dengan menggunakan indera peraba. Langkah-langkah yg Anda perlu diperhatikan adalah: a) Ciptakan lingkungan yg kondusif, nyaman dan santai b) Tangan Anda harus dalam keadaan kering, hangat, kuku pendek c) Semua bagian nyeri dilakukan palpasi yg paling akhir.

$>$ Perkusi, adalah: pemeriksaan yang dapat Anda lakukan dengan mengetuk, dengan tujuan untuk membandingkan kiri-kanan pada setiap daerah permukaan tubuh dengan menghasilkan suara. Perkusi bertujuan untuk: mengidentifikasi lokasi, ukuran, bentuk dan konsistensi jaringan. Contoh suara-suara yang dihasilkan: Sonor, Redup, Pekak, Hipersonor/timpani.

Auskultasi, Auskultasi, adalah merupakan pemeriksaan yang dapat Anda lakukan dengan mendengarkan suara yg dihasilkan oleh tubuh dengan menggunakan stetoskop.

Diagnosa pada keperawatan di tetapkan berdasarkan analisis dan interprestasi data yang didapatkan dari pengkajian klien Diagnosa keperawatan yang memberikan gambaran tentang kesehatan nyata (aktual) dan kemungkinan akan terjadi, dimana pengambilan keputusan dapat dilakukan dalam batas wewenang perawat. Diagnosa keperawatan juga sebagai suatu mutu bagian dari proses keperawatan yang di refleksikan dalam standar praktik american Nurses Assation (ANA). Standar standar ini, Menurut ( Nurjamah, 2012) dalam menentukan diagnosa keperawatan yang mungkin muncul pasien. untuk itu maka selalu perlu dilakukan pengkajian keprawatan untuk mempermudah perawat dalam menentukan diagnosa yang di alami oleh pasien. Yang perlu dilakukan adalah sebagai berikut : 
1. Pengkajian tanda tanda vital.

2. Pengkajian untuk keamanan

3. Pengkajian untuk situasi khusus pengkajian untuk klien hamil

4. Pengkajian untuk sistem perkemihan

5. Pengkajian aktifitas, isrirahat, dan mobilitas pergerakan

6. Pengkajian kenyamanan, kulit dan integritas kulit jaringan

7. Pengkjian untulk nutrsi

8. Pengkajian kondisi fisiologi

9. Pengkajian untuk kognetif dan persefsi

10. Pengkajian untuk spiritual, values dan regilius

11. Pengkajian untuk tingkah laku

Tujuan diagnosa keperawatan Tujuan diagnosa keperawatan untuk mengidentifikasi menurut Wahid \& Suprapto (2012) sebagai berikut: Masalah dimana adanya respon klien terhadap status kesehatan atau penyakit, Faktor faktor yang menyebabkan suatu masalah, Kemampuan klien untuk menyelesaikan masalah, Mengkomunikasikan masalah klien pada tim kesehatan yang lainnya, Mendemonstrasikan tanggung jawab dalam indentifikasi masalah klien, Mengidentifikasi masalah utama untuk perkembangan intervensi keperawatan.

Penentuan bagian dari diagnosa keperawatan, bagaimanapun lebih sulit dan kompleks dari pada penentuan diagnosa medis. Hal itu dikarenakan data dari hasil pengkajian tidak selalu menjadi data batasan karakteristik (S) dalam format PES pada diagnosa keperawatan, tetapi juga bisa menjadi etiologi (E) pada format PES. Data ini bahkan bisa berfungsi sebagai label dignosa itu sendiri ( Herdman 2012 ) diagnosa keperawatan menurut carperto ( 2001) Dapat di bedakan menjadi diangnosa keperawatan aktual, resiko kemungkinan dan kesejahteraan diagnosa keperawatan, dapat di jelaskan sebagai berikut

1. Aktual diagnosa keperawatan mengambarkan penilaian klinis yang yang baru volidasi oleh perawat karena adanya batasan karakteristik mayor jenis keperawatan tersebut memiliki tempat komponenen, di mulai dari label yang di berikan juga harus singkat dan jelas, hal itu bertujuan untuk mempermudah dalam membantudan membedakan dignosa yang ada agar dapat di bedakan antara diagnosa yang satu dengan diagnosa yang lainya menegakkan suatu diangnosa keperawatan maka di perluka adanya problem, entiologi. 
2. Resiko diagnosa keperawatan menggambarkan penilaian klinis dimana individu maupun kelompok lebih rentan mengalami masalah yang sama di bandingkan orang laindi dalam situasi yang sama atau serupa. Syarat untuk menegakkan diagnosa resiko ada unsur PE (Problem and Etiologi ) dan untuk penggunaan batasan karakteristik yaitu: resiko dan resiko tinggi “ tergantung dari tingkat kerentanan/keparahan suatu masalah

3. Kemungkinan diagnosa kemungkinan merupakan diagnosa keperawatan yang memerlukan data tambahan, bertujuan untuk mencegah adanya suatu diagnosa yang bersifat sementara, dan dalam menentukan suatu diagnosa keperawatan yang bersifat sementara bukanlah menunjukan suatu kelemahan atau keraguan dalam menentukan suatu diagnosa, akan tetapi merupakan suatu proses penting dalam keperawatan.

4. Kesejahteraan diagnosa keperawatan kesejahteraan merupakan penilaian klinis tentangkeadaan individu, keluarga atau masyarakat dalam transisi dari tingkat sejahtera tertentumenjadi tingakat sejahtera yang lebih tinggi (Herdman, 2007).

\section{Penutup}

\section{a.kesimpulan}

Proses keperawatan merupakan suatu proses yang sistematis dalam pengumpulan data dari berbagai sumber data untuk mengevaluasi dan mengidentifikasi status kesehatan klien.Pengkajian keperawatan merupakan dasar pemikiran dalam memberikan asuhan keperawatan sesuai dengan kebutuhan klien. Pengkajian yang lengkap, dan sistematis sesuai dengan fakta atau kondisi yang ada pada klien sangat penting untuk merumuskan suatu diagnosa keperawatan dan dalam memberikan asuhan keperawatan sesuai dengan respon individu.

Diagnosa pada keperawatan di tetapkan berdasarkan analisis dan interprestasi data yang didapatkan dari pengkajian klien Diagnosa keperawatan yang memberikan gambaran tentang kesehatan nyata (aktual) dan kemungkinan akan terjadi, dimana pengambilan keputusan dapat dilakukan dalam batas wewenang perawat. Diagnosa keperawatan juga sebagai suatu mutu bagian dari proses keperawatan yang di refleksikan dalam standar praktik american Nurses Assation (ANA). Standar standar ini, Menurut ( Nurjamah, 2012) dalam menentukan diagnosa keperawatan yang mungkin muncul pasien. untuk itu maka selalu perlu dilakukan pengkajian 
keprawatan untuk mempermudah perawat dalam menentukan diagnosa yang di alami oleh pasien.

b. saran

Setiap tindakan yang dilakukan diharapkan perawat selalu ada dengan pengumpulan data yang baik dan benar dengan proses proses yang sudah ditentukan sehingga setelah melakukan pengumpulan data dengan benar maka perawat dapat menentukan diagnosa dengan benar tanpa ada kesalahan karena telah mengumpulkan data dengan fakta dan kebenarannya ada.

Daftar pustaka

- Budiono. (2016). Konsep Dasar Keperawatan. Jakarta: Pubsdik SDM Kesehatan.

- JURNAL KEPERAWATAN 'AISYIYAH (JKA) Volume 5 | Nomor 1 | Juni 2018

- Dermawan, D. (2012). Proses Keperawatan Penerapan Konsep \& Karangka Kerja. Yogyakarta: Gosyen.

- Nurjanah, I. 2012.ISDA (Intan’s Screening Diagnosis Assesment.Yogyakarta: Moco Media.

- JURNAL ILMIAH KEPERAWATAN SAI BETIK, IDENTIFIKASI DIAGNOSIS KEPERAWATAN PADA PASIEN DI RUANG PARU SEBUAH RUMAH SAKIT Vol 11, No 1 (2015)

- PPNI.(2016). Standar Diagnosis Keperawatan Indonesia.Jakarta : DPP PPNI

- Rachmania D, (2016) Pengembangan Instrumen Penegakan diagnosis Keperawatan Berbasis SDKI Penelitian Action Research Di Ruang Teratai RSUD AM Pare Kediri. Thesis, Universitas Airlangga

- $\quad$ P RINAWATI, REPOSTORI, UNIMUS.AC.ID 2018.

- Rutami. (2012, Oktober). Pelaksanaan Proses Pengkajian Keperawatan di Ruang Rawat Inap RSUP H. Adam Malik Medan. Jurnal Keperawatan, 1(2). 
- Doenges, Marilynn E., Moorhouse, Mary Frances., Murr., Alice C. (2013) Nursing Diagnosis Manual: Planning, Individualizing, and Documenting Client Care4th Edition

- Suryono, Nugroho Christianto.2020. Kompetensi Perawat Mendokumentasikan Diagnosis Keperawatan Berdasarkan Standar Diagnosis Keperawatan Indonesia (SDKI). Jurnal Ilmu Kesehatan. Vol (11) No (1) tahun 2020

- Simamora, R. H., Bukit, E., Purba, J. M., \& Siahaan, J. (2017). Penguatan kinerja perawat dalam pemberian asuhan keperawatan melalui pelatihan ronde keperawatan di rumah sakit royal prima medan. Jurnal pengabdian kepada masyarakat, 23(2), 300-304.

- Simamora, R. H. (2019). Socialization of Information Technology Utilization and Knowledge of Information System Effectiveness at Hospital Nurses in Medan, North Sumatra. Editorial Preface From the Desk of Managing Editor..., 10(9). 